\title{
B7-H3 promotes the proliferation, migration and invasiveness of cervical cancer cells and is an indicator of poor prognosis
}

\author{
YI LI, JINGJING ZHANG, SAI HAN, QIUHONG QIAN, QIAN CHEN, \\ LU LIU and YOUZHONG ZHANG
}

\begin{abstract}
Department of Obstetrics and Gynecology, Qilu Hospital, Shandong University, Jinan, Shandong 250012, P.R. China
\end{abstract}
Received December 4, 2016; Accepted June 7, 2017

DOI: $10.3892 /$ or.2017.5730

\begin{abstract}
B7-H3 is an immune regulatory molecule whose aberrant expression in tumors is associated with adverse outcomes. Upregulation of B7-H3 may promote tumor cell proliferation and metastasis in vitro, but the role of B7-H3 in cervical cancer has not yet been investigated. We measured B7-H3 expression in 90 cervical cancer patient and 20 non-cervical lesion patient tissues using immunohistochemistry and in 30 cervical cancer patient and 30 healthy donor blood samples using ELISA. The association of B7-H3 expression and the prognosis of cervical cancer patients was investigated. B7-H3 knockdown in CaSki and SiHa cell lines was performed using small hairpin (sh)RNA lentiviral transfection and B7-H3 overexpression in CaSki and HeLa cell lines was performed using plasmid-vector lentivirus transduction. Cell proliferation, invasion and migration were then measured using MTT and Transwell assays in vitro. B7-H3 expression was significantly higher in the cervical cancer tissues compared to that noted in the normal cervical tissues (mean 72.22 vs. $15.00 \%$; p<0.001). Using Kaplan-Meier and Cox analyses, our data revealed that patients with strong intensity staining were significantly more likely to have a worse prognosis. The B7-H3 level in cervical cancer patient blood was significantly higher than that in the normal donors $(13.41 \pm 6.12$ vs. $9.90 \pm 3.16 \mathrm{ng} / \mathrm{ml}$; $\mathrm{p}=0.007)$. MTT assay revealed that high expression of B7-H3 promoted cervical cancer cell proliferation. Transwell assay data revealed that high expression of B7-H3 enhanced cervical cancer cell migration and invasion (CaSki, $\mathrm{p}=0.003$; HeLa, $\mathrm{p}=0.03$ ). In conclusion, expression of B7-H3 was significantly higher in cervical cancer tissues compared to normal cervical tissues, and this high expression was associated with worse prognosis for cervical cancer
\end{abstract}

Correspondence to: Professor Youzhong Zhang, Department of Obstetrics and Gynecology, Qilu Hospital, Shandong University, 107 Wenhua Xi Road, Jinan, Shandong 250012, P.R. China E-mail: zhangyouzhong@sdu.edu.cn

Key words: B7-H3, cervical cancer, prognosis, proliferation, migration, invasion patients. In addition, B7-H3 promoted proliferation, invasion and migration of cervical cancer and may be a potential target for treating cervical cancer.

\section{Introduction}

Cervical cancer, one of the most common gynecological malignancies worldwide, threatens the health of women (1). It has been reported that $80 \%$ of cervical cancer cases occur in developing countries and that persistent high-risk human papilloma virus (HPV) infection is closely related to the occurrence of cervical cancer $(2,3)$. However, not all women infected with high-risk HPV progress to cervical cancer, and few progress to squamous intraepithelial lesions (SIL). Moreover, women who get infected with HIV and who take immunosuppressive agents are more likely to develop SIL or cervical cancer (4). Thus, immune factors may be related to the pathogenesis of cervical cancer.

The B7 immunoregulatory family includes B7-1 (CD80), B7-2 (CD86), B7-H1 (PD-L1), B7-H2 (ICOSL), B7-DC (PD-L2), B7-H3 (CD276) and B7-H4 (B7X) (5). B7s play a crucial role in regulating adaptive immune response. The B7:CD28 superfamily can promote $\mathrm{T}$ cell activation or inhibit the $\mathrm{T}$ cell response (6). B7-H3 (or B7 homolog 3, CD276) was identified by database searches of a human dendritic cell-derived cDNA library in 2001 (7). In addition, Zhang et al found soluble B7-H3 in human serum/plasma in 2008 (8). B7-H3 has 2 forms: 2Ig- and 4Ig-B7-H3. 2Ig-B7-H3 has extracellular IgV-IgC domains and is present in both mouse and human cells, whereas 4 Ig-B7-H3 consists of tandemly duplicated IgV-IgC-IgV-IgC domains and is only expressed in human cells $(9,10)$. B7-H3 is widely expressed in various organs such as lung, breast, liver, placenta, the prostate and in dendritic cells. In addition, B7-H3 expression was elevated in several cancer cell lines or tumor tissues, including prostate, brain, pancreatic, breast, endometrial, liver, colorectal and oral cancers, and osteosarcomas and hematologic malignancies (11-23).

B7-H3 is similar in molecular structure to B7-H1 (PD-L1), and PD-L1 is associated with PD-1 and restrains T cell antitumor functions $(24,25)$. However, the function of B7-H3 in the immune response remains unclear. B7-H3 was originally discovered to costimulate proliferation of $\mathrm{CD}^{+}$and $\mathrm{CD}^{+}$ $\mathrm{T}$ cells, enhance induction of cytotoxic $\mathrm{T}$ cells and selectively stimulate interferon- $\gamma($ IFN- $\gamma)$ production in the presence of 
T cell receptor signaling (7). In sharp contrast, B7-H3 downregulated $\mathrm{T}$ helper type 1-mediated immune responses in a murine model (26). Mouse and human B7-H3 inhibited CD4 ${ }^{+}$ $\mathrm{T}$ cell activation and downregulated cytokine production (10).

B7-H3 was proven to influence tumor cell biological features in vitro and in vivo, but the role of $\mathrm{B} 7-\mathrm{H} 3$ in cancer is unclear. Immunohistochemical evidence suggests that high expression of B7-H3 in cancer tissues may be associated with disease spread and poor outcomes $(14,17,27)$. Recent functional studies revealed that high expression of B7-H3 may promote tumor cell metastatic ability $(18,28,29)$.

The role of $\mathrm{B} 7-\mathrm{H} 3$ and its expression in cervical cancer have not been extensively investigated. In the present study, we aimed to investigate the relationship between B7-H3 expression and the prognosis of cervical cancer patients and its potential mechanisms in cervical cancer in vitro.

\section{Materials and methods}

Patients and follow-up. The present study was approved by the Ethics Committee of Qilu Hospital, Shandong University [ethics approval code, KYLL-2014 (KS)-074]. Patient information was anonymized and de-identified. All participants joined the present study after providing informed consent.

Tissue and blood sample analysis. We identified 90 cervical cancer and 20 non-cervical lesion patients with tissue available in paraffin-embedded blocks who were treated at Qilu Hospital, Shandong University between 2009 and 2010. All cervical cancer patients were diagnosed with cervical cancer for the first time and no patient accepted adjuvant therapy prior to surgery. In addition, the exclusion criteria included: i) patients who also had autoimmune diseases; ii) patients who had received immunosuppressive drugs; iii) patients who were HIV-positive; iv) the presence of synchronous tumors; v) patients who had preoperative pelvic radiotherapy and vi) patients who had preoperative chemotherapy. Follow-up was carried out according to the National Comprehensive Cancer Network (NCCN) guidelines: every month in the first year; every third month in the second year; twice in the third, fourth and fifth years; and annually thereafter. After treatment, all patients were followed up until May 2016. Follow-up duration was calculated from the date of surgery to the date of death and/or the last follow-up.

In order to measure the B7-H3 level in blood samples, we identified 30 cervical cancer patients and 30 healthy donors who were treated at Qilu Hospital, Shandong University between 2015 and 2016. All cervical cancer patients were diagnosed with cervical cancer for the first time and no patient accepted adjuvant therapy prior to surgery. The inclusion criteria and exclusion criteria of the cervical cancer patients were the same as those described above. Patient blood samples were collected before surgery and were stored at $-80^{\circ} \mathrm{C}$. We measured serum B7-H3 of 30 cervical cancer patients and 30 healthy donors (catalog no. LS-F22755; LifeSpan Biosciences, Inc., Seattle, WA, USA).

Immunohistochemical (IHC) staining. The antibody used was anti-B7-H3 [1:100; 14058P; Cell Signaling Technology (CST) Danvers, MA, USA]. Staining was performed as described in the manual of an ultrasensitive streptavidin-peroxidase kit (PV-9001; ZSGB-Bio, Beijing, China). IHC staining was evaluated by 2 gynecological pathologists blinded to patient outcomes. The percent of tumor cells positive for B7-H3 were recorded in $25 \%$ intervals: 0 , no positive cells; $1,1-25 \%$ positive cells; $2,26-50 \%$ positive cells; $3,51-75 \%$ positive cells; and 4,76-100\% positive cells; and IHC intensity was recorded as: 0 , no staining; 1 , weak staining; 2 , moderate staining and 3 , strong staining. The 2 scores were then added to get the final score as follows: $0-3,(-) ; 4-5,(+) ; 6-7,(++)$.

Enzyme-linked immunosorbent assay (ELISA). Patient blood samples were collected before surgery and stored at $-80^{\circ} \mathrm{C}$. Serum B7-H3 was measured in cervical cancer and healthy donors samples using ELISA (catalog no. LS-F22755; LifeSpan Biosciences, Inc.).

Cell lines and cell culture. HeLa, SiHa and CaSki, human cervical cancer cell lines, were obtained from the American Type Culture Collection (ATCC; Manassas, VA, USA). Cells were cultured in Roswell Park Memorial Institute (RPMI)1640 (Gibco, Thermo Fisher Scientific, Waltham, MA, USA) medium containing 10\% fetal bovine serum (FBS) (Clark, Houston, TX, USA), at $37^{\circ} \mathrm{C}$ in a $5 \% \mathrm{CO}_{2}$ incubator.

Immunofluorescent staining. CaSki, SiHa and HeLa cells were cultured $\left(4 \times 10^{4}\right.$ cells/well $)$ in 24 -well plates, and incubated at $37^{\circ} \mathrm{C}$ in a $5 \% \mathrm{CO}_{2}$ incubator overnight. CaSki, $\mathrm{SiHa}$ and HeLa cells were washed 3 times with phosphatebuffered saline (PBS), fixed in 4\% cold paraformaldehyde for $15 \mathrm{~min}$, permeabilized with $0.2 \%$ Triton X-100 for $10 \mathrm{~min}$ and blocked in $10 \%$ goat serum. Then the cells were stained with mouse anti-B7-H3 monoclonal antibody (1:400; ab105922; Abcam, Cambridge, MA, USA) at $4^{\circ} \mathrm{C}$ overnight. Cells were washed with PBS 3 times, and incubated with secondary antibody (1:200; ZSGB-Bio) at room temperature in the dark. After staining with 4',6-diamidino-2-phenylindole (DAPI) (Beyotime Institute of Biotechnology, Shanghai, China) away from light for $3 \mathrm{~min}$, the cells were photographed under an Olympus IX51 inverted microscope (Olympus, Tokyo, Japan).

Generation of stable cell lines. The human B7-H3 (gene ID: 80381; NM_001024736) targeting small hairpin (sh)RNA sequence and a negative non-targeted control sequence were used to generate recombinant lentiviral particles. Both sequences were designed by the GenePharma Company (Shanghai, China). The targeting sequence of B7-H3 was 5'-GUGCUGGAGAAAGAUCAAATTUUUGAUCUUUCU CCAGCACTT-3'. The transfected cells included the B7-H3 shRNA (KD) and negative non-targeted control (NC) group, and the non-transfected cells were controls $(\mathrm{CON})$. These 3 groups were used for the following experiments.

We transfected HeLa and CaSki cells with the B7-H3 plasmid (GenePharma Company). The empty plasmid was also designed by GenePharma Company, and used as a negative control. The transfected cells included LV-B7-H3 (LV) and negative non-targeted control (NC) group, and the nontransfected cells were the control (CON) group.

This recombinant lentivirus was prepared and titered for $1 \times 10^{9} \mathrm{TU} / \mathrm{ml}$ (transfection units). Cells were cultured at 
Table I. Correlation of B7-H3 expression with clinicopathological characteristics of the cervical cancer cases.

\begin{tabular}{|c|c|c|c|c|}
\hline \multirow[b]{2}{*}{ Characteristics } & \multirow{2}{*}{$\begin{array}{l}\text { No. of pts. } \\
\quad(n=90)\end{array}$} & \multicolumn{2}{|c|}{$\begin{array}{c}\text { B7-H3 } \\
\text { expression }\end{array}$} & \multirow[b]{2}{*}{ P-value } \\
\hline & & Low & High & \\
\hline Age (years) & & & & 0.142 \\
\hline $18-45$ & 40 & 22 & 18 & \\
\hline $46-70$ & 50 & 35 & 15 & \\
\hline FIGO stage & & & & $<0.001$ \\
\hline I & 60 & 48 & 12 & \\
\hline II-III & 30 & 9 & 21 & \\
\hline Differentiation & & & & 0.491 \\
\hline Well & 17 & 12 & 5 & \\
\hline Moderate or poor & 73 & 45 & 28 & \\
\hline Histology & & & & 0.152 \\
\hline $\begin{array}{l}\text { Squamous cell } \\
\text { carcinoma }\end{array}$ & 74 & 44 & 30 & \\
\hline $\begin{array}{l}\text { Adenocarcinoma } \\
\text { and adenosquamous } \\
\text { carcinoma }\end{array}$ & 16 & 13 & 3 & \\
\hline
\end{tabular}

FIGO, International Federation of Gynecology and Obstetrics; pts., patients.

$1 \times 10^{5}$ cells/well into 6 -well tissue culture plates overnight. The lentiviral supernatant was added into cells and the multiplicity of infection (MOI) was 10. After transfection, the puromycin dihydrochloride was used to generate stable cell lines. Western blot analysis was performed to confirm the silencing or overexpression of B7-H3.

Western blotting. Cells were lysed on ice and protein was extracted using RIPA, PMSF and NaF (100:1:1; Beyotime Institute of Biotechnology). Protein was measured using a BCA protein assay kit (TianGen, Beijing, China). Then, $30 \mu \mathrm{g}$ protein was separated with SDS-PAGE and transferred onto polyvinylidene fluoride membranes. Membranes were blocked with $5 \%$ non-fat dry milk and then incubated with primary antibodies at $4{ }^{\circ} \mathrm{C}$ overnight. Primary antibodies were anti-B7-H3 $(1: 1,000 ; 14058 \mathrm{P})$ and anti-GAPDH $(1: 1,000$ dilution) (both from CST). Membranes were washed 3 times with Tris-buffered saline and Tween-20 (TBST) and incubated with secondary antibodies. Signals were quantified using ImageQuant LAS 4000 (General Electric Company, Fairfield, CT, USA). Data were analyzed with ImageJ [National Institutes of Health (NIH), Bethesda, MD, USA].

Cell migration and invasion assays. For the migration and invasion assays, $7 \times 10^{4}$ cells were resuspended in serum-free medium and placed on the membrane of chambers (Corning, New York, NY, USA). For the invasion assay, the membrane was covered with Matrigel (1:9 dilution; BD Biosciences, Franklin Lakes, NJ, USA). The lower chambers contained medium with $20 \%$ FBS. Following 24 h of incubation, the migrating cells in the lower chamber or invading cells on the bottom of each well were stained with Giemsa (Solarbio, China) followed by fixation in methyl alcohol for $30 \mathrm{~min}$. Then, the number of cells in 6 randomly selected microscopic fields (magnification, x200) was counted with an Olympus IX51 inverted microscope.

Cell viability assay. Cell viability was assessed using the MTT assay. Cells of each group were plated at 2,000 cells/well in a 96-well plate for 24,48 or $72 \mathrm{~h}$. At each time point, $20 \mu \mathrm{l} \mathrm{MTT}$ was added into each 96-well plate. After incubation at $37^{\circ} \mathrm{C}$ for $4 \mathrm{~h}$ the MTT solution was removed. Dimethyl sulfoxide $(100 \mu \mathrm{l})$ was added to each well and evaluated at $490 \mathrm{~nm}$ with Infinite M200 PRO (Bio-Rad Laboratories, Hercules, CA, USA).

Statistical analysis. Statistical analysis was performed using SPSS 19.0 software (IBM Corporation, Armonk, NY, USA). Results were presented as means \pm SD. Prognosis after surgery was estimated using the Kaplan-Meier method. The association between expression of B7-H3 and tumor-node-metastasis (TNM) stage was analyzed using the Spearman correlation method. Associations of B7-H3 with cancer-specific survival were evaluated with Cox models. Immunohistochemistry was assessed with the Chi-squared test. Quantitative data comparisons were performed using a Student's t-test and one-way analysis of variance (ANOVA). A p-value $<0.05$ was considered to indicate statistical significance.

\section{Results}

Clinical and pathological features and patient outcomes. The mean age of the 90 cervical cancer patients was $44.66 \pm 10.11$ years (range, 22-70 years). According to the International Federation of Gynecology and Obstetrics (FIGO) stage, 12 patients were in stage Ia; 48 were in stage Ib; 23 were in stage IIa; 3 were in stage IIb; and 4 were in stage IIIb. Median follow-up time was $5.54 \pm 1.60$ years. At the last followup, 13 patients had died from cervical cancer and the median survival period of these 13 patients was $2.11 \pm 1.58$ years.

Immunohistochemical staining. B7-H3 expression level in the cervical cancer patient group was significantly higher than that in the normal patient group (mean 72.22 vs. $15.00 \%$; $\mathrm{p}<0.001$ ). Immunohistochemical staining significantly revealed overexpressed B7-H3 in the tumor tissues and positive staining for B7-H3 expression was detected in the cytoplasm of the cervical cancer cells (Fig. 1). Strong intensity was found in $33(36.67 \%)$ of the cervical cancer patients, and patients with strong intensity staining were significantly more likely to have worse prognosis (Kaplan-Meier method; $p=0.004$; Fig. 2). As shown in Table I, the frequency of B7-H3 high expression was significantly higher in patients with stage II/III (21/30) compared to those with stage I $(12 / 60 ; \mathrm{p}<0.001)$. B7-H3 expression was correlated with TNM stage $(\mathrm{r}=0.509 ; \mathrm{p}<0.001)$ and the 5-year survival rate for patients with strong expression of B7-H3 was significantly lower than those patients with negative to moderate expression (94.8 vs. $71.9 \%$; $\mathrm{p}=0.004)$. In a multivariable Cox regression model, incorporation of age, histology, differentiation, clinical stage and B7-H3 expression revealed 

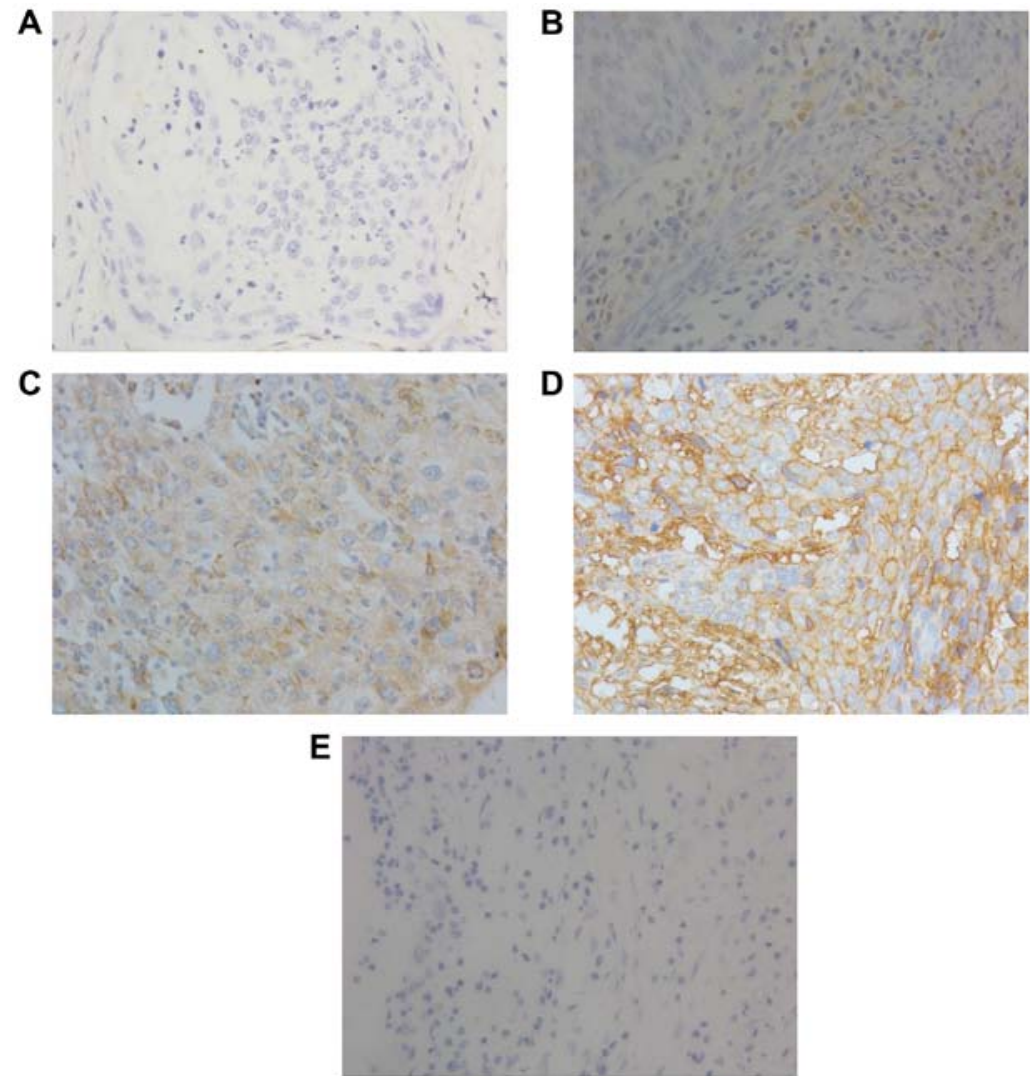

Figure 1. Immunohistochemical staining results of B7-H3 for negative, weak, moderate and strong staining in cervical cancer tissues. (A) Negative, (B) weak, (C) moderate and (D) strong staining in cervical cancer tissues, and (E) negative staining in normal cervical tissue. (magnification, $\mathrm{x} 400$ ).

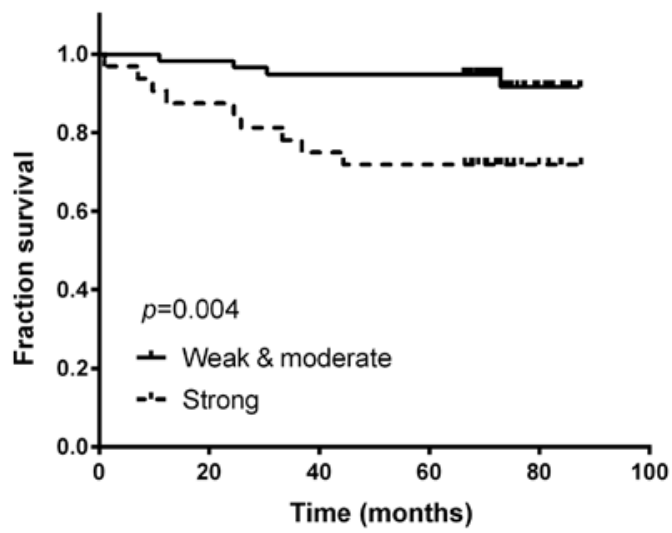

Figure 2. Correlation of overall survival and B7-H3 expression. Solid line represents negative to moderate intensity, and the dashed line represents strong intensity.

that patients with high expression of B7-H3 were significantly more likely to die from cervical cancer [HR, $4.463 ; 95 \%$ confidence interval $(\mathrm{CI}), 1.12-17.8 ; \mathrm{p}=0.035]$ compared with those with moderate or weak expression.

ELISA. Serum B7-H3 was measured in normal donors and cervical cancer patients and $\mathrm{B} 7-\mathrm{H} 3$ in cervical cancer patients was significantly higher than that noted for the normal donors (13.41 \pm 6.12 vs. $9.90 \pm 3.16 \mathrm{ng} / \mathrm{ml}$; $\mathrm{p}=0.007$ ) (Fig. 3).

Immunofluorescent staining. Cellular localization of B7-H3 in cervical cancer cell lines was studied with immunofluo-

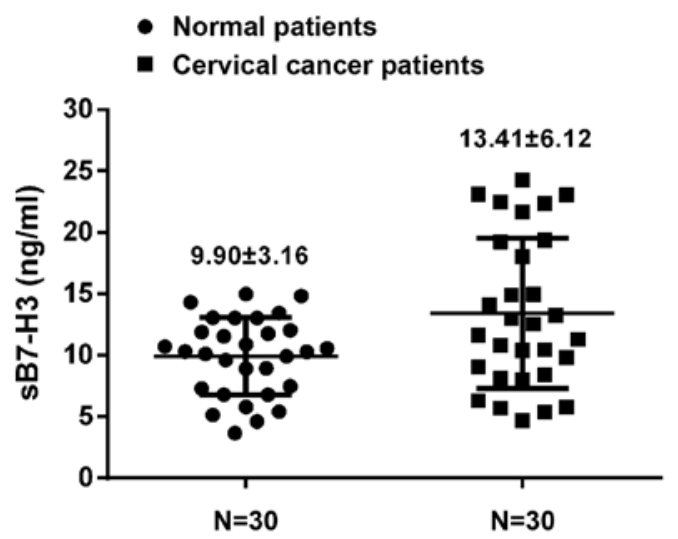

Figure 3. Expression of serum B7-H3 in healthy women and cervical cancer patients.

rescence in CaSki, SiHa and HeLa cell lines and B7-H3 was mostly distributed in the cytoplasm (Fig. 4).

B7-H3 upregulation and downregulation in cervical cancer cell lines. After infection with a lentiviral vector, $\mathrm{HeLa}, \mathrm{CaSki}$ and $\mathrm{SiHa}$ cells were assessed using western blotting (Fig. 5). Lentiviral infection was efficient and the data revealed that upregulation and downregulation of the $\mathrm{B} 7-\mathrm{H} 3$ gene was stable and efficient.

Cell migration and invasion assay. To investigate whether B7-H3 influences tumor migration and invasion, Transwell 

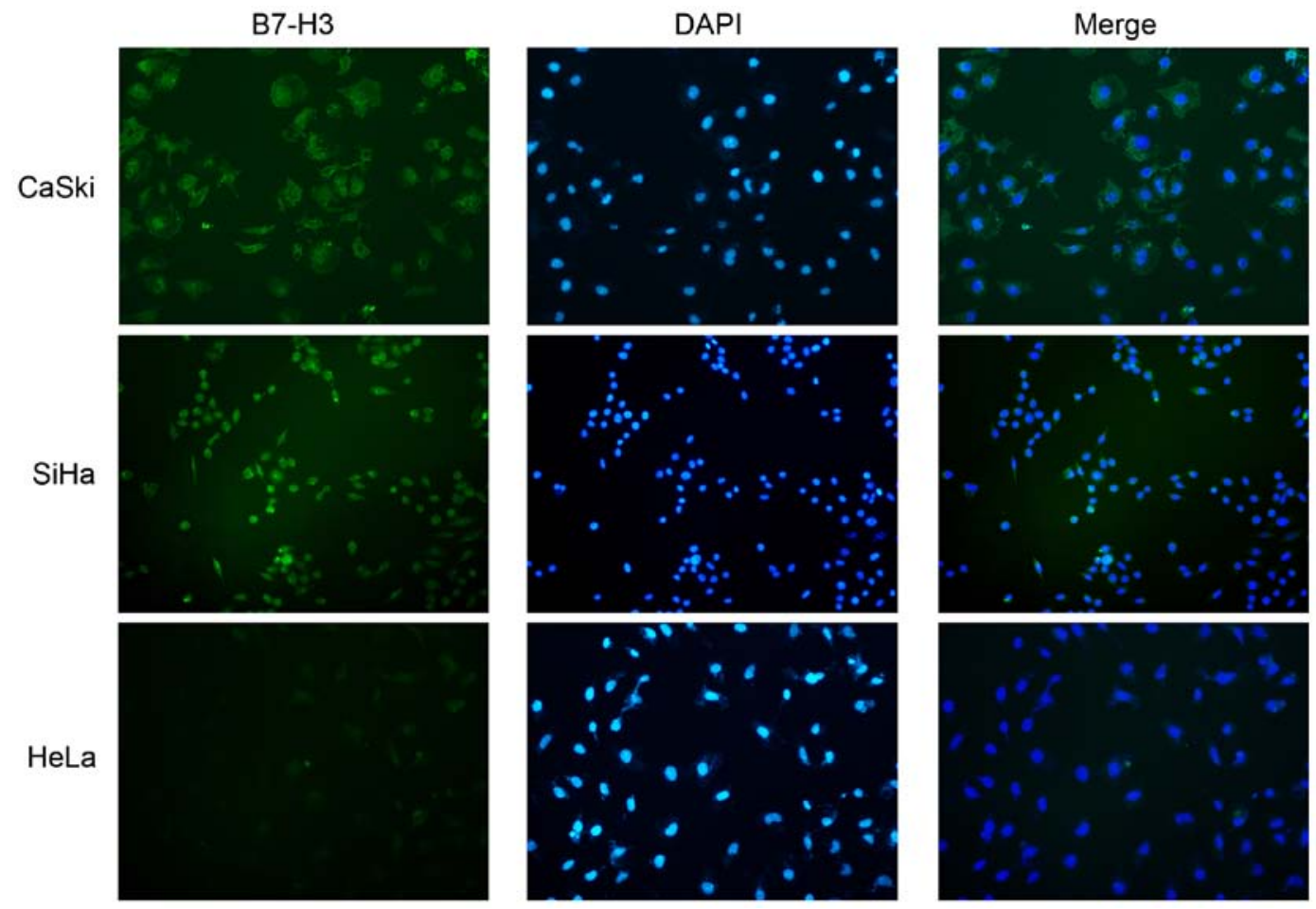

Figure 4. CaSki, SiHa and HeLa cell lines stained with B7-H3 to label cytoplasm and with DAPI to label nucleus (magnification, x200).

A

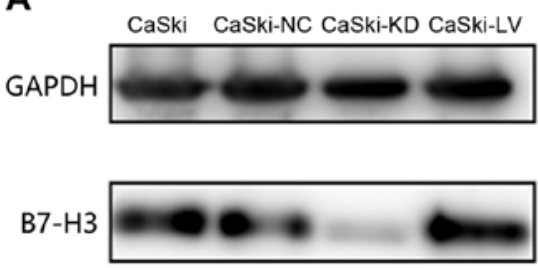

D

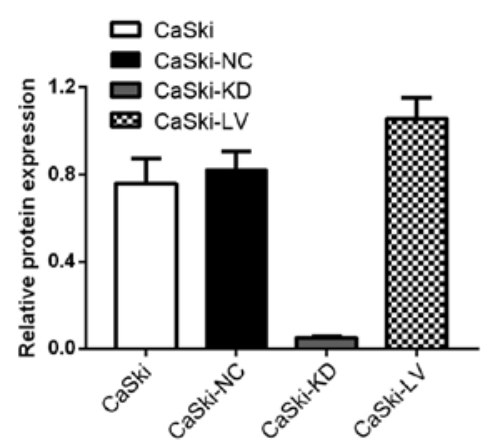

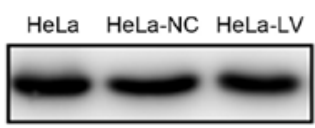

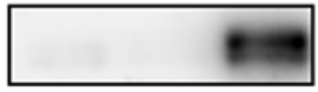

$\mathbf{E}$

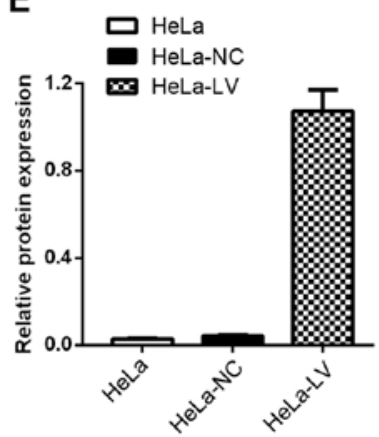

C
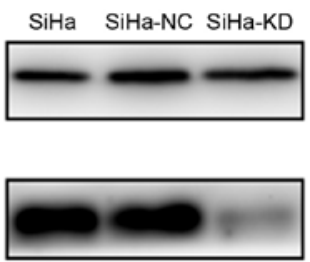

$\mathbf{F}$

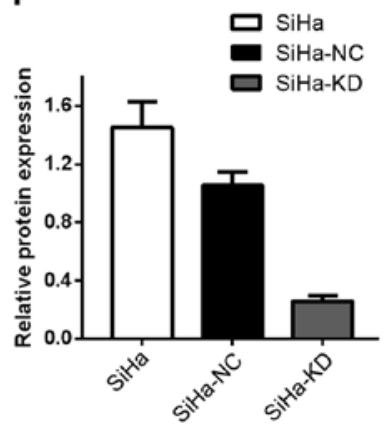

Figure 5. Protein expression of B7-H3 in CaSki, HeLa and SiHa cell lines after transfection and their control groups quantified by western blotting. (A) CaSki cell line. (B) HeLa cell line. (C) SiHa cell line. (D) Quantification of protein expression in A. (E) Quantification of protein expression in B. (F) Quantification of protein expression in $\mathrm{C}$.

migration and invasion assays were used to compare cell migration and invasiveness in each group, and Fig. 6 shows that KD-B7-H3 cell migration to the lower chamber was significantly reduced after $24 \mathrm{~h}$ of incubation compared to the controls (CaSki, $\mathrm{p}=0.001$; $\mathrm{SiHa}, \mathrm{p}=0.005$ ). In contrast, migration of LV-B7-H3 cells was increased (CaSki, $\mathrm{p}=0.003$; HeLa, $\mathrm{p}=0.03)$.
Cell viability assay. MTT assay was used to measure whether B7-H3 influenced cervical cancer cell viability, and data showed that cell viability declined in the KD-B7-H3 groups at 24, 48 and $72 \mathrm{~h}$ (Fig. 7) compared to the normal controls (CaSki, $\mathrm{p}=0.026$; $\mathrm{SiHa}, \mathrm{p}<0.001)$. LV-B7-H3 group viability was significantly increased compared to the normal controls (CaSki, p=0.009; HeLa, p<0.001). 
A

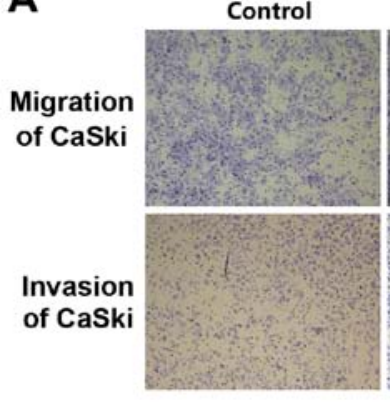

B

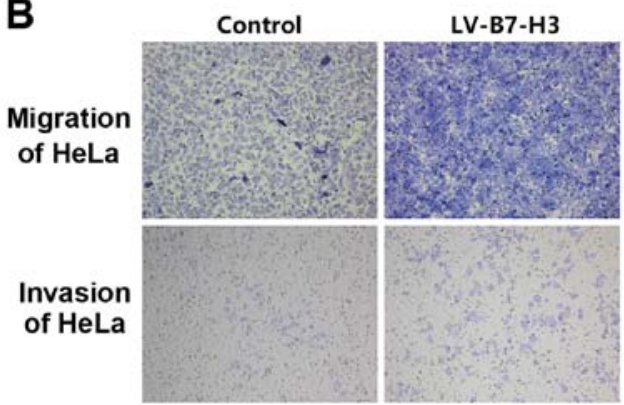

LV-B7-H3
KD-B7-H3

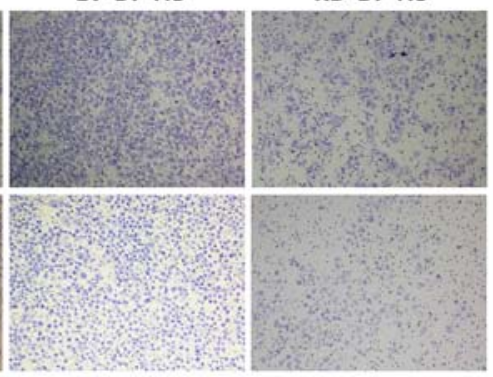

KD-B7-H3

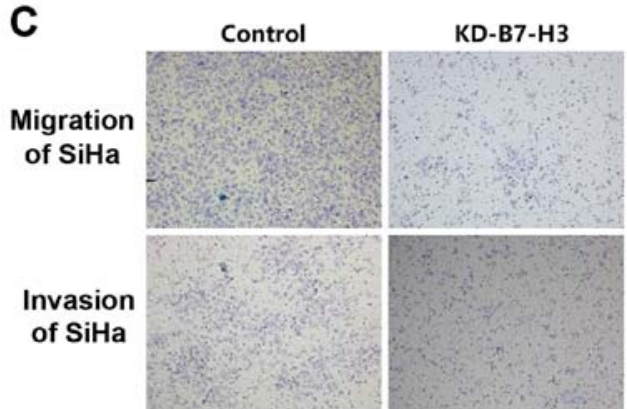

D

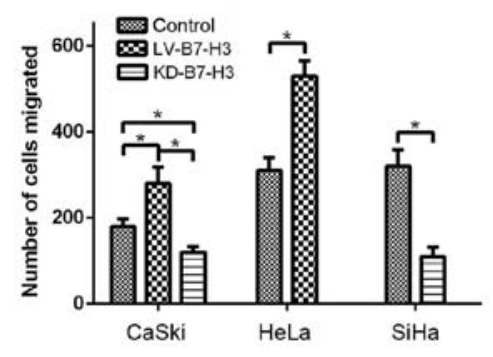

E

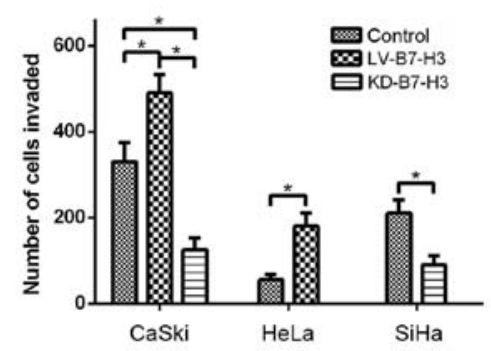

Figure 6. Effect of B7-H3 on migration and invasion of CaSki, HeLa and SiHa cell lines (magnification, x100). (A) Upregulation of B7-H3 increased CaSki cell migration and invasiveness; downregulation of B7-H3 decreased CaSki cell migration and invasiveness. (B) Upregulation of B7-H3 increased HeLa cell migration and invasiveness. (C) Downregulation of B7-H3 decreased SiHa cell migration and invasiveness. (D and E) Quantification of A-C. ${ }^{*} \mathrm{p}<0.05$.
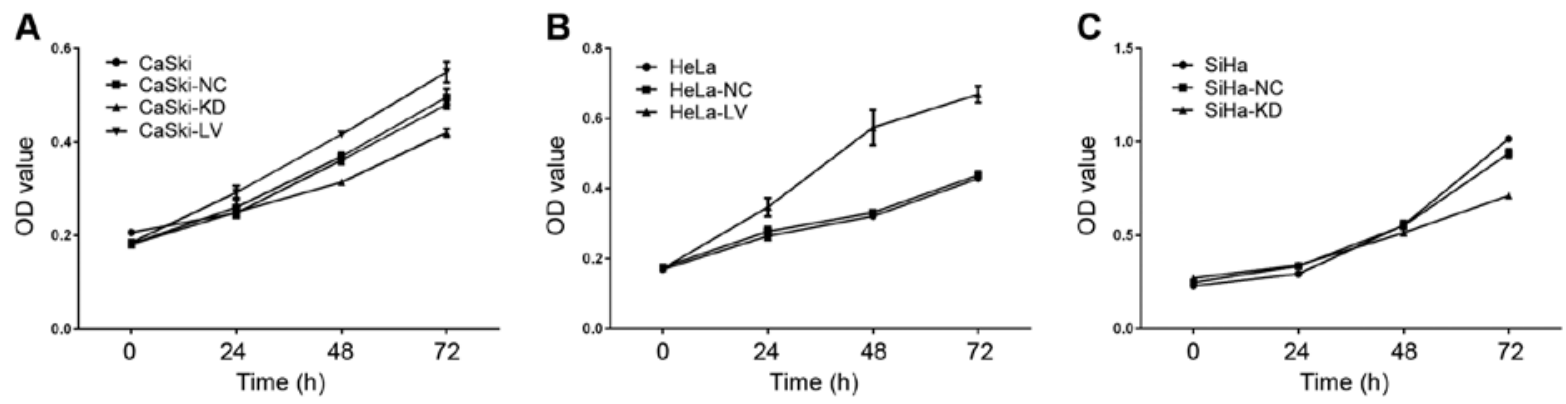

Figure 7. The role of B7-H3 in cell viability. (A) CaSki, CaSki-NC, CaSki-KD and CaSki-LV groups were cultured for 0, 24, 48 and $72 \mathrm{~h}$, and cell viability was measured via MTT assay. (B) HeLa, HeLa-NC and HeLa-LV groups were cultured for 0, 24, 48 and $72 \mathrm{~h}$, and cell viability was measured via MTT assay. (C) $\mathrm{SiHa}, \mathrm{SiHa}-\mathrm{NC}$ and $\mathrm{SiHa}-\mathrm{KD}$ groups were cultured for 0, 24, 48 and $72 \mathrm{~h}$, and cell viability was measured using MTT assay.

\section{Discussion}

B7-H3 is a B7 ligand family member discovered in 2001 (7). Recent studies indicate that $\mathrm{B} 7-\mathrm{H} 3$ is linked to tumor malignancy, but its clinical and functional significance in cervical cancer is unclear. To the best of our knowledge, we offered the first study of the role of B7-H3 in cervical cancer proliferation and metastasis in vitro. Using immunohistochemistry, we measured B7-H3 expression and noted that B7-H3 was signifi- cantly higher in cervical cancer than that noted in normal cervical tissues $(\mathrm{p}<0.001)$, and patients with strong intensity staining were significantly more likely to have worse prognosis $(\mathrm{p}=0.004)$. We also demonstrated that $\mathrm{B} 7-\mathrm{H} 3$ promoted cervical cancer cell proliferation, migration and invasiveness in vitro.

The immune system is key to preventing HPV viral oncogenesis and tumor progression (30). In an adaptive immune response, activation of $\mathrm{T}$ cells requires 2 signals: 
first $\mathrm{T}$ cell receptors recognize peptides presented by major histocompatibility complexes (MHCs) on antigen presenting cells; secondly, co-stimulatory molecules provide the second signal (6). The B7:CD28 superfamily is crucial for regulating adaptive cellular immunity, not only elevating $\mathrm{T}$ cell activation, but also inhibiting $\mathrm{T}$ cell responses by providing positive or negative second signals $(6,31)$. The B7-1:CD28 pathway delivers positive signals for $\mathrm{T}$ cell activation and survival; however, the B7-2:CTLA4 (cytotoxic T lymphocyte-associated antigen 4) pathway inhibits the T cell response (32). Moreover, B7s may contribute to tumor cell proliferation, migration and invasion (33-36). B7-H3 is a B7 ligand family member first discovered to play a stimulatory role in antitumor immune response in gastric carcinoma and in a lymphoma model, B7-H3 inhibited tumor growth and induced an antitumor response $(37,38)$. However, in other human tumors, such as renal clear cell carcinoma and prostate cancer, high expression of B7-H3 was related to adverse clinicopathological features and poor outcomes and B7-H3 was thought to promote tumor progression $(39,40)$. Reasons for such discrepancies are not clear and screening the $\mathrm{B} 7-\mathrm{H} 3$ receptor may help clarify the confusion. Other than immunological functions, B7-H3 can promote tumor cell proliferation and invasion in vitro and downregulation of B7-H3 expression may enhance tumor cell sensitivity to chemotherapeutic drugs according to recent functional studies $(16,29,41,42)$. In the present study, we investigated the relationship between $\mathrm{B} 7-\mathrm{H} 3$ and the progression of cervical cancer.

We have shown that B7-H3 was aberrantly expressed in cervical cancer tissues and higher expression of B7-H3 in cervical cancer patients may be associated with poor prognosis. ELISA data indicated that sB7-H3 was significantly higher in the cervical cancer patients blood samples compared to healthy donors. Our results were consistent with the studies in context of other tumors. Arigami et al revealed that high B7-H3 expression in breast cancer cells was a tumor progression factor and was associated with the extent of regional nodal metastasis (14). Increased B7-H3 in prostate cancer represented an independent predictor of disease spread and poor outcomes $(11,27)$. Crispen et al suggested that B7-H3 could be an independent prognostic factor for clear cell renal cancer (39). High B7-H3 expression was also associated with lymph node metastasis and TNM stage in non-small cell lung cancer (43). Wang et al found that osteosarcoma patients with higher B7-H3 expression had shorter survival and time to tumor recurrence (18). The results of the present study indicate that B7-H3 may be a new prognostic factor for cervical cancer.

To further explore whether B7-H3 is associated with tumor metastasis, invasion and migration assays in vitro were performed, and data showed that high expression of B7-H3 promoted cervical cell migration and invasion. B7-H3 had also been approved to play a role in the metastasis of other tumors. Xie et al demonstrated that soluble B7-H3 significantly promoted migration and invasion of pancreatic cancer cells (41). B7-H3 overexpression in a prostate cancer cell line (PC-3) significantly increased migration and invasiveness of PC-3 cells (44). Downregulation of B7-H3 inhibited the migratory potential and Matrigel invasiveness of melanoma cells and B7-H3 could be a potential therapeutic target for antimetastatic therapy (29).
Previous functional studies indicated that B7-H3 had a critical role in tumor cell line proliferation. Zhang et al showed that B7-H3 silencing significantly inhibited U937 cell growth (42). In mantle cell lymphoma, high expression of B7-H3 promoted tumor proliferation in vitro and in a mouse model (45). In the present study, our results revealed that downregulation of B7-H3 significantly inhibited cervical cancer cell growth in vitro, conversely, upregulation of B7-H3 significantly promoted cervical cancer cell growth. These results indicated that $\mathrm{B} 7-\mathrm{H} 3$ could enhance tumor progression and $\mathrm{B} 7-\mathrm{H} 3$ might be a potential therapeutic target for cervical cancer.

In summary, to the best of our knowledge, this is the first study to suggest a clinical and functional role of B7-H3 in cervical cancer. Our results indicated that aberrant B7-H3 expression might be associated with poor prognosis and B7-H3 affected cervical cancer cell proliferation and metastasis in vitro. Study limitations include a small sample size and a lack of data validation in vivo. The molecular biological mechanisms of B7-H3 in metastasis and progression of cervical cancer warrant further study.

\section{Acknowledgements}

The present study was supported by the National Natural Science Foundation of China (grant no. 81572559).

\section{References}

1. Arbyn M, Castellsagué X, de Sanjosé S, Bruni L, Saraiya M, Bray F and Ferlay J: Worldwide burden of cervical cancer in 2008. Ann Oncol 22: 2675-2686, 2011.

2. Akhtar-Danesh N, Lytwyn A and Elit L: Five-year trends in mortality indices among gynecological cancer patients in Canada. Gynecol Oncol 127: 620-624, 2012.

3. Crow JM: HPV: The global burden. Nature 488: S2-S3, 2012.

4. Prabha Devi K and Bindhu Priya N: Conventional Pap smear screening in HIV seropositive women in South India. J Obstet Gynaecol India 63: 55-58, 2013.

5. Hofmeyer KA, Ray A and Zang X: The contrasting role of B7-H3. Proc Natl Acad Sci USA 105: 10277-10278, 2008.

6. Leung $J$ and Suh WK: The CD28-B7 family in anti-tumor immunity: Emerging concepts in cancer immunotherapy. Immune Netw 14: 265-276, 2014.

7. Chapoval AI, Ni J, Lau JS, Wilcox RA, Flies DB, Liu D, Dong H, Sica GL, Zhu G, Tamada K, et al: B7-H3: A costimulatory molecule for $\mathrm{T}$ cell activation and IFN-gamma production. Nat Immunol 2: 269-274, 2001.

8. Zhang G, Hou J, Shi J, Yu G, Lu B and Zhang X: Soluble CD276 (B7-H3) is released from monocytes, dendritic cells and activated $\mathrm{T}$ cells and is detectable in normal human serum. Immunology 123: 538-546, 2008.

9. Sun M, Richards S, Prasad DVR, Mai XM, Rudensky A and Dong C: Characterization of mouse and human B7-H3 genes. J Immunol 168: 6294-6297, 2002.

10. Ling V, Wu PW, Spaulding V, Kieleczawa J, Luxenberg D, Carreno BM and Collins M: Duplication of primate and rodent B7-H3 immunoglobulin V- and C-like domains: Divergent history of functional redundancy and exon loss. Genomics 82: 365-377, 2003

11. Roth TJ, Sheinin Y, Lohse CM, Kuntz SM, Frigola X, Inman BA, Krambeck AE, McKenney ME, Karnes RJ, Blute ML, et al: B7-H3 ligand expression by prostate cancer: A novel marker of prognosis and potential target for therapy. Cancer Res 67: 7893$7900,2007$.

12. Xu H, Cheung IY, Guo HF and Cheung NKV: MicroRNA miR-29 modulates expression of immunoinhibitory molecule B7-H3: Potential implications for immune based therapy of human solid tumors. Cancer Res 69: 6275-6281, 2009. 
13. Yamato I, Sho M, Nomi T, Akahori T, Shimada K, Hotta K, Kanehiro H, Konishi N, Yagita $\mathrm{H}$ and Nakajima Y: Clinical importance of B7-H3 expression in human pancreatic cancer. $\mathrm{Br}$ J Cancer 101: 1709-1716, 2009.

14. Arigami T, Narita N, Mizuno R, Nguyen L, Ye X, Chung A, Giuliano AE and Hoon DSB: B7-h3 ligand expression by primary breast cancer and associated with regional nodal metastasis. Ann Surg 252: 1044-1051, 2010.

15. Brunner A, Hinterholzer S, Riss P, Heinze G and Brustmann $\mathrm{H}$ : Immunoexpression of B7-H3 in endometrial cancer: Relation to tumor T-cell infiltration and prognosis. Gynecol Oncol 124: 105-111, 2012.

16. Sun TW, Gao Q, Qiu SJ, Zhou J, Wang XY, Yi Y, Shi JY, Xu YF, Shi YH, Song K, et al: B7-H3 is expressed in human hepatocellular carcinoma and is associated with tumor aggressiveness and postoperative recurrence. Cancer Immunol Immunother 61: 2171-2182, 2012

17. Ingebrigtsen VA, Boye K, Tekle C, Nesland JM, Flatmark K and Fodstad O: B7-H3 expression in colorectal cancer: Nuclear localization strongly predicts poor outcome in colon cancer. Int J Cancer 131: 2528-2536, 2012.

18. Wang L, Zhang Q, Chen W, Shan B, Ding Y, Zhang G, Cao N, Liu L and Zhang Y: B7-H3 is overexpressed in patients suffering osteosarcoma and associated with tumor aggressiveness and metastasis. PLoS One 8: e70689, 2013.

19. Zhao X, Li DC, Zhu XG, Gan WJ, Li Z, Xiong F, Zhang ZX, Zhang GB, Zhang XG and Zhao H: B7-H3 overexpression in pancreatic cancer promotes tumor progression. Int J Mol Med 31: 283-291, 2013

20. Chen C, Shen Y, Qu QX, Chen XQ, Zhang XG and Huang JA: Induced expression of B7-H3 on the lung cancer cells and macrophages suppresses T-cell mediating anti-tumor immune response. Exp Cell Res 319: 96-102, 2013.

21. Hu Y, Lv X, Wu Y, Xu J, Wang L, Chen W, Zhang W, Li J, Zhang S and Qiu H: Expression of costimulatory molecule B7-H3 and its prognostic implications in human acute leukemia. Hematology 20: 187-195, 2015.

22. Chen JT, Chen CH, Ku KL, Hsiao M, Chiang CP, Hsu TL, Chen $\mathrm{MH}$ and Wong $\mathrm{CH}$ : Glycoprotein $\mathrm{B} 7-\mathrm{H} 3$ overexpression and aberrant glycosylation in oral cancer and immune response. Proc Natl Acad Sci USA 112: 13057-13062, 2015.

23. Guery T, Roumier C, Berthon C, Renneville A, Preudhomme C and Quesnel B: B7-H3 protein expression in acute myeloid leukemia. Cancer Med 4: 1879-1883, 2015.

24. Iwai Y, Ishida M, Tanaka Y, Okazaki T, Honjo T and Minato N: Involvement of PD-L1 on tumor cells in the escape from host immune system and tumor immunotherapy by PD-L1 blockade Proc Natl Acad Sci USA 99: 12293-12297, 2002.

25. Topalian SL, Drake CG and Pardoll DM: Targeting the PD-1/ B7-H1(PD-L1) pathway to activate anti-tumor immunity. Curr Opin Immunol 24: 207-212, 2012.

26. Suh WK, Gajewska BU, Okada H, Gronski MA, Bertram EM, Dawicki W, Duncan GS, Bukczynski J, Plyte S, Elia A, et al: The B7 family member B7-H3 preferentially down-regulates T helper type 1-mediated immune responses. Nat Immunol 4: 899-906, 2003.

27. Zang X, Thompson RH, Al-Ahmadie HA, Serio AM, Reuter VE, Eastham JA, Scardino PT, Sharma P and Allison JP: B7-H3 and $\mathrm{B} 7 \mathrm{x}$ are highly expressed in human prostate cancer and associated with disease spread and poor outcome. Proc Natl Acad Sci USA 104: 19458-19463, 2007.

28. Lemke D, Pfenning PN, Sahm F, Klein AC, Kempf T, Warnken U, Schnölzer M, Tudoran R, Weller M, Platten M, et al Costimulatory protein $4 \mathrm{IgB} 7 \mathrm{H} 3$ drives the malignant phenotype of glioblastoma by mediating immune escape and invasiveness. Clin Cancer Res 18: 105-117, 2012.
29. Tekle C, Nygren MK, Chen YW, Dybsjord I, Nesland JM, Maelandsmo GM and Fodstad O: B7-H3 contributes to the metastatic capacity of melanoma cells by modulation of known metastasis-associated genes. Int J Cancer 130: 2282-2290, 2012.

30. Tindle RW: Immune evasion in human papillomavirus-associated cervical cancer. Nat Rev Cancer 2: 59-65, 2002.

31. Greenwald RJ, Freeman GJ and Sharpe AH: The B7 family revisited. Annu Rev Immunol 23: 515-548, 2005.

32. Chen L: Co-inhibitory molecules of the B7-CD28 family in the control of T-cell immunity. Nat Rev Immunol 4: 336-347, 2004.

33. Chen X, Wang L, Wang W, Zhao L and Shan B: B7-H4 facilitates proliferation of esophageal squamous cell carcinoma cells through promoting interleukin-6/signal transducer and activator of transcription 3 pathway activation. Cancer Sci 107: 944-954, 2016.

34. Cheng L, Jiang J, Gao R, Wei S, Nan F, Li S and Kong B: B7-H4 expression promotes tumorigenesis in ovarian cancer. Int $\mathrm{J}$ Gynecol Cancer 19: 1481-1486, 2009.

35. Abadi YM, Jeon H, Ohaegbulam KC, Scandiuzzi L, Ghosh K, Hofmeyer KA, Lee JS, Ray A, Gravekamp C and Zang X: Host b7x promotes pulmonary metastasis of breast cancer. $\mathrm{J}$ Immunol 190: 3806-3814, 2013.

36. Salceda S, Tang T, Kmet M, Munteanu A, Ghosh M, Macina R, Liu W, Pilkington $\mathrm{G}$ and Papkoff J: The immunomodulatory protein $\mathrm{B} 7-\mathrm{H} 4$ is overexpressed in breast and ovarian cancers and promotes epithelial cell transformation. Exp Cell Res 306: 128-141, 2005.

37. Sun X, Vale M, Leung E, Kanwar JR, Gupta R and Krissansen GW: Mouse B7-H3 induces antitumor immunity. Gene Ther 10: 1728-1734, 2003.

38. Wu CP, Jiang JT, Tan M, Zhu YB, Ji M, Xu KF, Zhao JM, Zhang GB and Zhang XG: Relationship between co-stimulatory molecule B7-H3 expression and gastric carcinoma histology and prognosis. World J Gastroenterol 12: 457-459, 2006.

39. Crispen PL, Sheinin Y, Roth TJ, Lohse CM, Kuntz SM, Frigola X, Thompson RH, Boorjian SA, Dong H, Leibovich BC, et al: Tumor cell and tumor vasculature expression of $\mathrm{B} 7-\mathrm{H} 3$ predict survival in clear cell renal cell carcinoma. Clin Cancer Res 14: 5150-5157, 2008

40. Benzon B, Zhao SG, Haffner MC, Takhar M, Erho N, Yousefi K, Hurley P, Bishop JL, Tosoian J, et al: Correlation of B7-H3 with androgen receptor, immune pathways and poor outcome in prostate cancer: An expression-based analysis. Prostate Cancer Prostatic Dis 20: 28-35, 2017.

41. Xie C, Liu D, Chen Q, Yang C, Wang B and Wu H: Soluble B7-H3 promotes the invasion and metastasis of pancreatic carcinoma cells through the TLR4/NF- $\kappa$ B pathway. Sci Rep 6: 27528, 2016.

42. Zhang W, Wang J, Wang Y, Dong F, Zhu M, Wan W, Li H, Wu F, Yan X and Ke X: B7-H3 silencing by RNAi inhibits tumor progression and enhances chemosensitivity in U937 cells. Onco Targets Ther 8: 1721-1733, 2015.

43. Mao Y, Li W, Chen K, Xie Y, Liu Q, Yao M, Duan W, Zhou X, Liang R and Tao M: B7-H1 and B7-H3 are independent predictors of poor prognosis in patients with non-small cell lung cancer. Oncotarget 6: 3452-3461, 2015.

44. Yuan H, Wei X, Zhang G, Li C, Zhang X and Hou J: B7-H3 over expression in prostate cancer promotes tumor cell progression. J Urol 186: 1093-1099, 2011.

45. Zhang W, Wang Y, Wang J, Dong F, Zhu M, Wan W, Li H, Wu F, Yan X and Ke X: B7-H3 silencing inhibits tumor progression of mantle cell lymphoma and enhances chemosensitivity. Int J Oncol 46: 2562-2572, 2015. 